- Carlos E. C. Martins

- Rogério L. R. Videira

- Gleicy K. Barcelos

\section{Parada cardiorrespiratória em obeso mórbido e reanimação com massagem cardíaca subdiafragmática}

\author{
Hospital e Maternidade São Luiz, São Paulo
}

INTRRDUCְÃa

A anestesia no obeso mórbido é um desafio. As complicaçôes são freqüentes e, muitas vezes, de difícil tratamento.

\section{RELATD DO CASD}

Paciente feminina, 59 anos, $138 \mathrm{~kg}, 1,56 \mathrm{~m}$, índice de massa corpórea $(\mathrm{IMC})=56,7 \mathrm{~kg} / \mathrm{m}^{2}, \mathrm{P} 2$ (antigo ASA II), hipertensa. Tratada com atenol + clortalidona, foi submetida à gastroplastia redutora por laparotomia. Monitorização com cardioscópio, capnografia, oxímetro de pulso, pressão arterial média (PAM) e pressão venosa central (PVC) (v. jugular interna direita). Técnica anestésica combinada: anestesia geral e raquianestesia em L3/L4, agulha 27 G x 411116 . Foram utilizados bupivacaína hiperbárica $(5 \mathrm{mg})$ + sufentanil $10 \mathrm{mcg}+$ morfina $0,5 \mathrm{mg}$ intratecal. A anestesia geral foi induzida com midazolan ( $2 \mathrm{mg})$, fentanil $(250 \mathrm{mcg})$, propofol $150 \mathrm{mg}$ e succinilcolina $160 \mathrm{mg}$. Manutenção com propofol em infusão alvo controlada $3,5 \mathrm{mcg} / \mathrm{ml}$, atracúrio $7 \mathrm{mcg} / \mathrm{kglmin}$, sevoflurano $0,5 \%$ e $\mathrm{N}_{2} \mathrm{O}$ a $50 \%$. Após $4 \mathrm{~h}$, a paciente apresentou bradicardia com repercussão hemodinâmica $(\mathrm{FC}=52 \mathrm{bpm}$, $\mathrm{PA}=6.032 \mathrm{mmHg}$ ), sendo medicada com atropina $0,75 \mathrm{mg}$. Evoluiu para fibrilação ventricular. Desfibrilada com $200 \mathrm{~J}$, apresentou assistolia. Iniciada MCE com PAM = 30/20 mmHg. Após $3 \mathrm{~min}$ e devido à ineficácia da MCE, passou-se para a massagem cardíaca subdiafragmática (MCSD), obtendo-se PAM $=60 \mathrm{mmHg}$. Depois de 20 min e cinco desfibrilaçōes alternadas com MCSD e $5 \mathrm{mg}$ epinefrina, a paciente assumiu ritmo sinusal e foi encaminhada à UTI com dopamina $5 \mathrm{mcg} / \mathrm{kglmin}$. Recebeu alta da UTI no quarto PO e alta hospitalar no $15^{\circ} \mathrm{PO}$.
DISCUSSÃロ

A partir de 1960, quando Kouwenhoven descreveu a MCE, a massagem cardíaca interna, outrora muito utilizada, passou a ter indicações restritas, não sendo rotineiramente preconizada nos algoritmos da American Hearth Association. No entanto, em algumas situaçôes, em que existem dificuldades técnicas que tornam a MCE ineficaz, poderiam ser usadas técnicas alternativas. A MCSD possui algumas vantagens durante a cirurgia com abdome aberto, como menor incidência de fratura de costelas e outras lesões. A compressão digital da aorta abdominal direciona o fluxo da massagem para os órgãos alvo da reanimação (coração e cérebro). Neste caso, o sucesso da reanimação prolongada pode ser creditado à utilização da técnica.

REFERÊNCIAS

Rieder CF. A study of the techniques of cardiac massage with the abdomen open. Surgery 1985;98(4):824-30;

2. Girardi, LN. Improved survival after intraoperative cardiac arrest in noncardiac surgical patients. Arch Surgery. 1995;130(1):15-8.

Endereço para correspondência:

Carlos Eduardo da Costa Martins

Rua Doutor Alceu de Campos Rodrigues, 95 - Itaim

São Paulo (SP) - CEP 04544-000 